\title{
FORMAS DE PRODUCCIÓN DE LAS COMUNIDADES INDÍGENAS PARA RESPONDER A LAS DEMANDAS DEL MERCADO GLOBALIZADO
}

\author{
Jairo Iván Cerón, ${ }^{79}$ Nancy Cabezas Burbano ${ }^{80}$
}

\begin{abstract}
RESUMEN
Las comunidades indígenas caucanas poseen sistemas de organización que connotan una base comunitaria para establecer un orden y un control social que se ve reflejado en sus sistemas productivos surgidos de emprendimientos colectivos, mediante producción agroecológica, bajo el concepto de cadenas productivas, autonomía alimentaria, sistemas de financiamiento alternativos, formas de comercialización locales y externas, formación de personal propio, investigación local, organización administrativa, gestión y planeación productiva, en renglones como turismo, cafés especiales, frutales, apicultura, plantas medicinales y aromáticas, quinua, amaranto, maderas, fique, leche, entre otros, bajo un concepto de participación, gobernabilidad local, sostenibilidad ambiental, equidad de género y generacional, y cuya finalidad es el fortalecimiento de su desarrollo endógeno y la participación justa en los mercados globales.
\end{abstract}

Palabras clave: diversidad étnica, minorías étnicas, mercados abiertos, desarrollo tecnológico, dependencia o interdependencia, relaciones económicas y de producción, formas de organización social, procesos de autodesarrollo, producción agroecológica, cadenas productivas, autonomía alimentaria, formas de comercialización.

\begin{abstract}
Indigenous communities have Caucana systems connotan an organization to establish a community-based order and social control, which is reflected in their productive systems arising from collective enterprises, through agro ecological production, under the concept of productive chains, food autonomy, systems financing alternative forms of local and external marketing, staff training itself, local research, administrative, management and productive planeacion, in lines such as tourism, specialty coffee, fruit, beekeeping, medicinal and aromatic plants, quinoa, amaranth, timber, fique, milk, among others, under a concept of participation, local governance, environmental sustainability, gender and generational equity and whose purpose is to strengthen its endogenous development and fair participation in global markets.
\end{abstract}

Key words: Ethnic diversity, ethnic minorities, open markets, technological development, dependence or interdependence, economical and production relationships, ways of social

79 CERÓN MUÑOZ, Jairo Iván. <jairo.ceron@unad.edu.co>

80 CABEZAS BURBANO, Nancy. <nancy.cabezas@unad.edu.co> 
organization, self-development processes, agro-ecologic production, productive chains, food self-sufficiency, commercialization ways.

Recibido: 16 de marzo de 2009

Aceptado: 17 de abril de 2009

\section{INTRODUCCIÓN}

El reconocimiento constitucional de la diversidad cultural, de la igualdad y la dignidad de todas las culturas que conviven en el país, y de los derechos colectivos de las minorías, introdujo el tema de interculturalidad a los procesos de desarrollo rural que, en regiones de convivencia multiétnica, cobran fuerza dado que comparten territorio indígenas, mestizos, campesinos y negros.

En el departamento del Cauca en Colombia, la comunidad asentada es multidiversa y multicultural. Se caracteriza la comunidad indígena por sus particularidades y, al tratar sus esquemas de producción, se aprecian sus sistemas productivos, sus formas de organización y su estructura social como referentes de importancia en el marco de cadena productiva.

\section{ANTECEDENTES Y MARCO CONCEPTUAL}

\section{Antecedentes}

La diversidad étnica y cultural es una realidad bastante evidente en todo el mundo, aún en aquellas sociedades que aparentemente han sido homogéneas en lo racial, en las costumbres, en la forma de organización, en lo lingüístico, lo económico y en su visión integral como comunidad. Las minorías étnicas, por lo general, no se sienten incluidas, invitadas ni representadas en una sociedad que supuestamente reconoce las diferencias sociales y culturales, una sociedad que a través de los estados pretende ver unidad racial, lingüística, religiosa y cultural, al tomar decisiones que están distantes de las realidades locales, en un contexto de presencia social y cultural muy diversa.

Con el fin de que las comunidades indígenas fueran artífices de su propio desarrollo económico, social, político, territorial, cultural, educativo y jurídico, el Estado desarrolló una legislación ${ }^{81}$ que posibilitara dichos fines, la cual requiere de procesos de acompañamiento institucional que propendan por su posicionamiento en los espacios de discusión y debate nacional, por lograr una mejor capacidad del personal local para asumir los retos de autogestión, formación, aprendizaje, fortalecimiento del marco normativo propio, del desarrollo comunitario integral y de la pervivencia como comunidades en el marco de sus propios valores culturales.

81 Artículo 7 y 8 de la Constitución. La Ley 21 de 1991 aprueba el Convenio 169 de la orT sobre pueblos indígenas y tribales en países independientes. 


\section{Marco conceptual}

Es innegable que hoy las minorías étnicas viven tiempos agitados en procesos mundiales de modernización, de mercados abiertos, de tecnologías de información y de comunicación, de desarrollo tecnológico, de crisis ambiental, de lucha y juegos de poder, de bloques económicos de dependencia o interdependencia, que generan crisis, cambios, luchas por la pervivencia y por la identidad de cada minoría. ${ }^{82}$ Vemos cómo en la construcción de estado nación algunos países vieron, en la diversidad cultural y étnica, un obstáculo para su visión de desarrollo, multidiversidad entendida como una herencia que se debía superar y que, por tanto, el camino debido sería formar ciudadanos libres e independientes para que puedan cumplir deberes que la sociedad, en general, les reconozca e imponga. Quienes no estuvieran por ende en este proceso de homogenización serían considerados como anormales dando pie a procesos de intolerancia que para las minorías ha significado sensaciones de inferioridad, de exclusión, base de procesos de rebeldía y resistencia para evitar su desaparición.

De ahí el concepto de resistencia de múltiples identidades locales y comunitarias, que para desarrollarlo, se replegaron hacia unas condiciones de marginalidad desde las cuales despliegan:

1. Lecturas de la modernidad que, de algún modo, fortalecían sus consensos internos

2. Actitudes instintivas y programáticas de resistencia a lo hegemónico

3. Discursos políticos que reclaman el reconocimiento de la autonomía y los derechos colectivos o la integración diferencial a las dinámicas del resto de la sociedad. ${ }^{83}$

Los primeros debates sobre el multiculturalismo se remontan a los primeros años de la década de los sesenta en países como Canadá y, más adelante, Australia, para luego generalizarse a aquellas naciones que por distintas razones comenzaron a sufrir cambios notorios en la composición demográfica producto de oleadas migratorias provenientes de regiones periféricas. Hoy es un tema de interés público que no sólo atañe a la región o a un país, porque abarca tanto grupos ancestrales preexistentes a la actual cultura como minorías de origen extranjero, sino porque junto al otorgamiento y reconocimiento de derechos colectivos, el Estado debía tratar de armonizar tradiciones, costumbres y filosofías de vida no siempre solidarias entre sí. ${ }^{84}$ «Son comunidades, pueblos y naciones indígenas los que, teniendo una continuidad histórica con las sociedades anteriores a la invasión y precoloniales que se desarrollaron en sus territorios, se consideran distintos de otros sectores de las sociedades que ahora prevalecen en esos territorios o en partes de ellos. Constituyen ahora sectores no dominantes de la sociedad y tienen la determinación de preservar, desarrollar y transmitir a futuras generaciones sus territorios ancestrales y su identidad étnica como base

82 FUNCOP. Elementos de Jurisdicción Especial indígena y prácticas comunitarias de justicia. Julio de 2001. p. 18.

83 Ibíd.

84 Ibíd. 
de su existencia continuada como pueblo, de acuerdo con sus propios patrones culturales, sus instituciones sociales y sus sistemas legales../ ${ }^{85}$

De acuerdo con información oficial, la población indígena en Colombia asciende a 785356 habitantes quienes son miembros de 82 pueblos y habitan en la mayoría de los departamentos y municipios del país. Los 638 resguardos legalmente constituidos ocupan el 27\% del territorio nacional, con un total de 31.3 millones de hectáreas tituladas a su favor. ${ }^{86} \mathrm{El}$ mayor peso poblacional indígena se encuentra en zonas de importancia ambiental: la Amazonía, la Orinoquía, el Litoral Pacífico, La Guajira, Cauca y la Sierra Nevada de Santa Marta. El 90\% de los indígenas habita en zonas rurales.

En el país existen cerca de 84 etnias o pueblos indígenas que cuentan con una población de 1 378884 personas (Dane, Censo 2005) que representan el 3,3\% del total nacional. La mayor parte de esta población habita en el área rural (78\%). En los 32 departamentos del país se encuentra ubicada población indígena, aunque en 25 de ellos se presenta una clara presencia de comunidades que habitan, en su mayoría, en resguardos (718), en aproximadamente 214 municipios, y en 12 corregimientos departamentales.

Están ubicados en los departamentos de Guaviare (0.75\%), Chocó (5.28\%), Putumayo (3.25\%), Nariño (11.04\%), Cauca (13.3\%), La Guajira (18.63\%), Amazonas (44\%), Vichada (3.27\%), Guainía $(1.68 \%)$ y Vaupés $(0.8 \%)$, donde además había 313 resguardos titulados. Los demás grupos están distribuidos en el resto del país. Los departamentos de Cauca, La Guajira y Nariño concentran más del 50\% del total de la población indígena nacional. El resto se distribuye en núcleos más pequeños en el resto del país. ${ }^{87}$

La Corte Constitucional ha armonizado la normativa constitucional y los tratados internacionales que en materia de derechos humanos ha ratificado el país; los derechos especiales orientados a la protección de la diversidad étnica y cultural forman parte del conjunto de los derechos humanos desarrollando así el concepto de «Bloque de Constitucionalidad».

En su artículo 7, la Constitución Política de Colombia promulga que «el estado reconoce y protege la diversidad étnica y cultural de la nación colombiana»y, en su artículo 8 señala que «Es obligación del Estado y las personas proteger las riquezas culturales y naturales de la nación».

El mundo indígena se concibe como una totalidad, donde no es posible explicar cada elemento como algo independiente, por eso, la tierra, como territorio, es un recurso vital, es la fuente de la vida. Significa entonces que su ambiente está ligado o integrado a lo productivo (económico), a lo social y a lo cultural y que la finalidad de la conservación de su propia cultura es hacer sustentable lo económico, lo social y lo cultural.

85 José Martínez Cobo. Descripción de los pueblos indígenas. Relator Naciones Unidas. <www.un.org/esa/socdev/pfii > $86<$ www.dnp.gov.co>

$87<$ www.dnp.gov.co $>$ 
«Los pueblos indígenas hemos desarrollado la lucha por construir nuestro proyecto de vida y este proceso histórico lo podemos sistematizar en tres fases: Primera, el desarrollo autónomo, donde se forma el hombre total, integral, en relación armónica con la naturaleza. Segunda, el choque cultural, la oposición cultura dominante-hombre dominado, donde se forma el hombre dependiente, sumiso y el hombre rebelde, malicioso, cerrado, y tercera, la proyección, para la cual se necesitan acuerdos y alianzas, para garantizar la vida el territorio y posteriormente se proyecta para reconstruir lo perdido».$^{88}$

Se parte de una definición: se entiende por sistemas de producción el conjunto de actividades que un grupo humano organiza, dirige y realiza de acuerdo a sus objetivos, cultura y recursos, utilizando prácticas en respuesta al medio físico que le rodea. ${ }^{89}$

Se reconoce en los espacios ocupados por las minorías étnicas, una serie de limitaciones para el desarrollo normal de las tareas inherentes a los diversos procesos productivos, como la carencia de elementos para el trabajo, de espacios funcionales, las instalaciones físicas inadecuadas y el desconocimiento de técnicas para el manejo y administración de la información y la documentación. Por tanto, la problemática se puede visualizar como deficiencia económica-productiva, técnico-administrativa y político-organizativa.

Antes de adentrarse en encadenamientos productivos en zonas indígenas del Cauca es importante señalar las diversas definiciones de cadena productiva igualmente válidas en diversos contextos productivos.

La cadena de producción en el sector agropecuario y agroindustrial abarca el conjunto de agentes económicos que participan directamente en la producción, transformación, comercialización, mercadeo y distribución de los bienes agropecuarios o agroindustriales. Una cadena es también un conjunto de actividades estrechamente interrelacionadas y verticalmente asociadas por su vinculación a un mismo producto o productos similares o derivados y cuya finalidad es satisfacer al consumidor. De esta forma el concepto de cadena agropecuaria se ha convertido en una herramienta útil de política pública para el desarrollo productivo y competitivo del sector agropecuario colombiano, a través de la cual se orientan y conciertan con el sector privado las políticas sectoriales agrícolas, de comercio exterior e industrial. El enfoque de cadena ha permitido superar la perspectiva limitada a la producción primaria, abarcando mejor la problemática compleja del sector, de las interacciones de los diferentes eslabones y de estos con su entorno (Ponencias FodePal Seminario sobre Alianzas, Cadenas Productivas y Competitividad para un Desarrollo Rural Sustentable. 2004).

IICA plantea que la cadena productiva es la «Integración de los productores con los diferentes actores que intervienen en los procesos de: producción, investigación, transferencia de tecnología, procesamiento, comercialización y financiación, que intervienen en la producción

88 YULE, Marcos. Ponencia sobre Educación Ambiental en los Pueblos Indígenas. 1996.

89 BERDEGUE, Julio y LARRAÍN, Bárbara. Cómo trabajan los campesinos. Cuadernillo de Información Agraria nro. 18. Temuco (Chile): Grupo de Investigaciones Agrarias. Universidad de Temuco. 1987. 
de un bien o servicios, complementarios, hacia la búsqueda de la productividad y la conquista de mercados».

Minicadenas productivas. Según Acción Social Presidencia de la República de Colombia de su proyecto Resa, las minicadenas productivas y sociales impulsan el desarrollo económico local, buscan organizar las actividades económicas que realizan en el territorio los pequeños y medianos productores y empresarios, articulando las etapas de producción, transformación, servicios y comercialización.

Se entiende por cadena productiva (Ministerio de Agricultura. Art. 1 Ley 118) el conjunto de actividades que se articulan técnica y económicamente desde que se inicia el proceso de producción de un producto hasta que se comercializa. Está constituida por todos los agentes que participan en la producción, la transformación, la comercialización y la distribución del producto. Es así como la cadena productiva está conformada por los tres niveles de la economía.

En el municipio de Inzá, desde hace cerca de una década, uno de los principales proyectos productivos que empezó a trabajar la Asociación de Cabildos de Inzá, Juan Tama, Asotama, creada en el año 1993, fue la comercialización del café tradicional.

Más tarde esta organización promovió también la ampliación de cultivos en zonas indígenas, y desde hace cinco años, con el decidido apoyo del Programa Tierradentro (años 2000-2005) se viene fortaleciendo estructuralmente en sus aspectos técnicos y administrativos de planeación y gestión para adelantar un proceso de conversión de sistemas productivos tradicionales en sistemas ecológicos de producción, al posicionar el producto en nichos de mercado, especialmente, de producción limpia y mercados justos, a nivel nacional e internacional.

El café en la región representa el 55\% de la economía de Tierradentro, con una producción en pergamino seco aproximada a las 3500 toneladas por año. Para las familias campesinas, indígenas y afrocolombianas dedicadas a su producción, este es un medio de intercambio comercial que les posibilita el acceso a bienes de consumo externos a la parcela como servicios básicos (salud y educación), adquisición de mercancías y apoyo a las infraestructuras productivas familiares.

El proyecto trabajó con 1800 productores —-familias— de los municipios de Páez e lnzá, de los cuales 312 fueron certificados por su trabajo orgánico. Las mujeres participantes en el proyecto, muchas de ellas cabeza de hogar, han encontrado en él la posibilidad de brindar a su familia una mejor calidad de vida, al dedicar un tiempo importante a la recolección, al beneficio y la selección del grano, así como también a la biodiversificación de los cultivos asociados.

Esta transición implicó una importante inversión en todos los eslabones de la agrocadena para posicionar en el mercado nacional y mundial la marca Café Tierradentro, como un producto certificado y reconocido por su origen, el manejo agronómico orgánico y, su valor socio-organizativo, cultural y étnico. 
El modelo de transición se concibió con una visión integral de uso sostenible del territorio y un fuerte sentido de responsabilidad ambiental y social. Se tuvieron en cuenta: el aprovechamiento de espacios culturales de trabajo colectivo como la minga y el cambio de mano; la recuperación de sistemas productivos amigables propios del saber tradicional, privilegiando la preparación local de insumos orgánicos para mejorar el suelo, la capa vegetal y las fuentes abastecedoras de agua; la instalación de cultivos, asociados con especies multipropósitos (árboles frutales, forrajeros, abonos verdes, gramíneas y leguminosas con destino al consumo humano y de los animales domésticos, mientras se proporciona sombrío y nutrición al suelo y a la planta); se trabajó en el fortalecimiento y la creación de formas organizativas y, por último, se destinó un importante recurso para la rotación de créditos destinado a las infraestructuras productivas y de comercialización tanto para los productores como para la Asociación de Cabildos de Inzá, Juan Tama, Asotama.

Los cerca de 2000 caficultores que participaron del proyecto de transición se organizaron en veintidós grupos - seis en zona campesina, quince en comunidades indígenas y uno en la comunidad afrocolombiana- que administran los diferentes Fondos de Comercialización, encargados de la compra local del producto y de coordinar el traslado del grano desde los centros primarios de acopio hasta el centro de comercialización Asotama.

Cada grupo, denominado junta local de productores orgánicos, tiene una mesa directiva, de la que hace parte un dinamizador o caficultor modelo. Representantes de estas juntas y la directiva de la Asociación de Cabildos de lnzá, Juan Tama, analizan avances del proyecto con miras a identificar las familias que pueden ser certificadas por sus esfuerzos en la caficultura orgánica. El gremio de caficultores hoy está organizado para dar sostenibilidad al proyecto y Asotama se consolida como empresa comunitaria con soporte administrativo-financiero y de gestión permanente, liderando las actividades de promoción de la caficultura orgánica, el acopio, transporte, la torrefacción, el empacado y la comercialización.

Para asegurar el desarrollo de las actividades propias y la adquisición de equipos y maquinaria pequeña, necesarios en el tránsito de la caficultura tradicional a la orgánica se previó el fortalecimiento del Fondo Rotatorio de Café que ya venía en marcha, cuyo propósito es hacer préstamos a los socios del proyecto. Así, se poblaron las áreas caficultoras de Tierradentro con secadores de café, despulpadoras, sistemas de manejo del residuo de cosecha y el montaje de semilleros de propagación vegetal, entre otros.

Estas importantes inversiones permitieron que Asotama concluyera la agrocadena productiva del café al realizar el montaje de la planta de procesamiento Agroindustrial de Café Tierradentro, con lo que hoy se garantiza el trabajo directo con los productores primarios, el procesamiento, el empacado y la venta del producto, desde la misma región.

Complementariamente se desarrolló la imagen corporativa de la marca Café Tierradentro y la estrategia publicitaria del producto. El Ministerio de Salud, por su parte otorgó el Registro Invima y aprobó la codificación del producto según el esquema EANUCC 13 o código de barras. 
Una década de trabajo con el café, a nivel de comercialización, de promoción del cultivo y finalmente de conversión a sistemas orgánicos de producción, le ha permitido a Asotama un acumulado de experiencias en este trabajo agroindustrial.

En su preocupación por hacer llegar al comprador la mayor información posible sobre el origen del grano, hace seguimiento de la familia y condiciones ambientales donde se produce el grano, es la llamada trazabilidad del café: cada socio del Proyecto tiene su propio código de identificación y de barras, lo que permite identificar condiciones de producción en todos los eslabones hasta llegar al empaque. El comprador, con el código de identificación puede conocer, desde cualquier lugar del mundo, a través de internet, en la página $<$ www. tierradentro.org $>$ la trayectoria del producto que va a consumir, el área de producción de donde proviene, la vivienda y el núcleo familiar de los productores y un pequeño testimonio familiar de la experiencia productiva.

A lo largo de estos cinco años, se aprovecharon eventos, ferias y encuentros, nacionales e internacionales para retroalimentar experiencias de gestión y negociación del producto. En este sentido Asotama ha participado consecutivamente en Agropecuarias Nacionales, AGROEXPO, escenario que se convirtió en la plataforma de lanzamiento de Café Tierradentro, y ha permitido numerosos contactos comerciales a nivel nacional e internacional.

Todo ello ha repercutido en la mejora de los canales de gestión y comercialización, lo que se refleja en un sobreprecio que reciben las familias productoras de café orgánico y en las posibilidades crecientes de consolidación de la empresa comunitaria.

A través del Plan de vida y el programa económico, la Asociación de Cabildos Juan Tama desarrolla los proyectos de café orgánico, reconversión ganadera y té de coca, siendo el primero el producto agrícola de mayor importancia, el cual le ha permitido a Asotama hacer contactos a nivel internacional, y exportar un promedio anual de 3489 toneladas de café pergamino seco, que se comercializan por múltiples vías.

Así mismo, y con el ánimo de organizar el turismo de esta zona, la Asociación Juan Tama ha liderado el programa de Plan Turístico de Tierradentro en el que ha estado acompañado por otras instituciones. De esta forma, se han ido describiendo algunos sitios sagrados y de interés turístico en la región.

A través de la Asociación de Cabildos Indígenas Juan Tama de Inzá, y con el apoyo financiero brindado por el convenio de cooperación internacional denominado Programa de Desarrollo Rural en la Región de Tierradentro, Cxab Wala, COL/B7-310/IB/96/109, entre la delegación de la Comisión Europea y la Red de Solidaridad Social; así como por la Corporación para la Reconstrucción de la Cuenca del río Páez y Zonas Aledañas, Nasa Kiwe; y con recursos propios de la Asociación, ha sido posible consolidar un equipo técnico de apoyo para la conversión de 1800 fincas tradicionales de producción de café natural (con sombra, sin químicos de síntesis) a sistemas de producción agroecológica, procesos que han involucrado el mejoramiento de las condiciones de producción, de recolección, beneficio húmedo del 
café, secado al sol, empacado, transporte y comercialización, con el objeto de incrementar el ingreso económico de las familias nativas de Tierradentro.

La economía de un total de 3528 familias, 1962 en Inzá y 1566 en Páez, se fundamenta en la producción de café en áreas de terreno que en promedio no superan las 1.2 hectáreas por familia. El café es un factor de intercambio comercial que posibilita el acceso a bienes de consumo externos a la parcela, a servicios básicos (salud, educación) o a recursos monetarios que permiten la adquisición de las mercancías necesarias para el desarrollo personal o individual. Por lo tanto, el café moviliza cerca del $70 \%$ de la economía inzaeña y el $50 \%$ de la economía de los paeces.

De Tierradentro sale un promedio anual de 3489 toneladas de café pergamino seco, las cuales se comercializan por múltiples vías (Almacafé, Cooperativa de Caficultores del Huila, Comité de Cafeteros de Inzá, Asorcafé, Asociación de Cabildos Juan Tama, inversionistas privados, intermediarios de ocasión y otros). Siendo reconocida a nivel mundial la calidad del café de Tierradentro y al haberse verificado que ello se debe a las características biótopoecológicas, las condiciones de cultivo y el beneficio en húmedo del grano, se crea desde la iniciativa de la Asociación de Cabildos Juan Tama de Inzá un proyecto que aproveche esta condición especial del café, pero que además incorpore en su proceso de producción y beneficio la especialidad de manejo agronómico a través de prácticas conscientes de agricultura ecológica o biológica.

Desarrollar un proceso de caficultora biológica es un reto técnico social y cultural que la Asociación Juan Tama ha asumido y que, con los apoyos financieros, técnicos, administrativos y de mercadeo del Programa Tierradentro, permite competir a nivel mundial con una calidad certificada de café reconocida por su origen, manejo agronómico, valor social, cultural y étnico, lo que se traduce en mejores precios de venta y, por lo tanto, en mayores ingresos para los caficultores asociados al proyecto.

Café Tierradentro expresa territorio, cultura y manejo (café orgánico) al brindar a sus consumidores café tipo exportación a precios asequibles, $\mathrm{y}$, buen pago a sus productores. Según el mapa del municipio de Páez, División de Resguardos, la Asociación de Cabildos Indígenas de Inzá, Juan Tama, fue la primera asociación de este tipo, en el Cauca.

En la actualidad, Asotama es el órgano representativo del pueblo indígena nasa que habita en el municipio de Inzá, al nororiente del departamento del Cauca. Tiene gran capacidad de convocatoria y legitimidad, y trabaja en el propósito de hacer prevalecer los usos y costumbres ancestrales, de fortalecer las organizaciones de base, de promover el desarrollo local y de proteger y consolidar sus autoridades tradicionales y su patrimonio etnocultural.

La Federación de Cabildos, Confederación, fue uno de los primeros ejemplos de agremiación de autoridades indígenas en Tierradentro, especialmente promovida por líderes de la región norte del municipio de Páez, pero fue a partir del desastre natural (sismo de 5,9 en la escala de Richter) del año 1994 que la idea tomó mayor fuerza. 
Con la ocurrencia de este fenómeno que afectó buena parte de la población indígena nasa, líderes de la región vieron la necesidad de aunar esfuerzos para impulsar el proceso de reconstrucción, lo que dio origen a la Asociación Nasa Çxhaçxha, que en lengua nasa yuwe significa fuerza Páez. Esta organización, trabaja desde aquel momento en la orientación, acompañamiento y ejecución de obras y acciones para normalizar la infraestructura vial, productiva y sociocultural de la región (educación, salud, vivienda, saneamiento básico, entre otras).

Con el fin de adelantar el desarrollo integral de las comunidades indígenas, se realizan las siguientes acciones:

- Actividades de carácter industrial y comercial, directamente o mediante convenios con personas naturales o jurídicas.

- Formulación de planes de vida, planes de desarrollo, planes de ordenamiento territorial.

- Fomento e impulso en las comunidades de proyectos de salud, educación, cultura, recreación y deporte, vivienda, medioambiente, producción, agua potable y saneamiento básico, en coordinación con las autoridades nacionales, internacionales, regionales y locales, o con entidades particulares.

- Capacitación administrativa y jurídica (desarrollo institucional, capacitación técnica agropecuaria y apropiación de tecnología e investigación).

- Elaboración y ejecución de proyectos productivos: comercialización de frutas, alimentos y abarrotes, producción de panela a través del Programa Agronasa (comercializadora nasa) y manejo de proyectos de infraestructura.

- Acciones que conducen al mejoramiento social, económico, cultural y al bienestar de las comunidades de la región.

El anterior es un claro ejemplo de la forma como se organizan los distintos actores de una comunidad indígena en torno a un proceso productivo que les permite ser competitivos en el contexto global. Los actores de una cadena asumen el liderazgo con el apoyo de instituciones, lo que hace que cuenten con autonomía y capacidad para definir y poner en práctica sus propias estrategias y mecanismos con el fin de explotar las nuevas oportunidades que les brinda el mercado.

Los actores centrales son las mismas comunidades y estas deben impulsar su propio desarrollo sin desconocer la participación y concertación con los actores institucionales, dado que las buenas relaciones sociales son las que permiten dar una respuesta oportuna a las demandas cambiantes del entorno.

De esta manera se concluye que la asociatividad, el desarrollo endógeno y la innovación se constituyen en factores fundamentales para que las comunidades indígenas residentes en el departamento del Cauca puedan competir en un mercado globalizado. 


\section{METODOLOGÍA}

Revisión bibliográfica en bases de datos multidisciplinarias como EBSCO, base de datos que ofrece textos completos, índices y publicaciones periódicas académicas que cubre diferentes áreas de las ciencias y las humanidades. Sus colecciones están disponibles a través de EBSCohost el cual es un sistema en línea que combina un contenido de gran calidad en una página atractiva, con herramientas únicas de búsqueda y recuperación de información. Los resultados de las búsquedas ofrecen enlaces a los textos completos de los artículos. La mayoría de los estudios encontrados se abordan desde la antropología y la sociología.

Igualmente, la base documental institucional aborda la temática desde los derechos humanos, la legislación para cumplimiento de protocolos internacionales y desde la intervención de grupos sociales según los objetivos institucionales.

De otra parte la información sobre sistemas productivos y organización hacen parte de la memoria histórica de los pueblos indígenas, en este caso del Páez.

\section{RESULTADOS Y DISCUSIÓN}

\section{Caracterización del sector indígena}

En Colombia coexiste una diversidad étnica conformada fundamentalmente por indígenas, afrocolombianos, raizales y rom. Frente a la etnia indígena, se señala que en Colombia existen más de 84 etnias, cuyas particularidades son las siguientes:

- Poseen cerca de 27 millones de hectáreas de tierra equivalente a una cuarta parte del país.

- Sus territorios corresponden a ecosistemas muy valiosos y a fronteras internacionales.

- Poseen autonomía para determinar sus propias formas de gobierno y organización.

- El Cauca es el segundo departamento con mayor población indígena y el sexto en población negra o afrocolombiana.

- Pueblos indígenas: Páez, Yanacona, Guambiano, Kokonuko, Totoró, Eperara Siapidara, Inga.

- Búsqueda del fortalecimiento de procesos organizativos que permitan mejorar las condiciones de convivencia sociocultural, económica y relacional con el medio ambiente.

- Posibilidades para asumir procesos de autodesarrollo.

\section{Formas de asociatividad}

- Base comunitaria constituida para establecer un orden y un control social

- Institucionalización de las relaciones sociales, los niveles de parentesco, la organización política y el ejercicio del poder.

- Tipos de autoridad: los chamanes y el cabildo 
- Formas de organización de territorio:

- Comunidades mestizas - juntas de acción comunal

- Comunidades negras - capitanías

- Comunidades indígenas - resguardos

- Organización social de los paeces: familia nuclear

- Los paeces habitan 96 resguardos en los departamentos de Cauca, Huila, Tolima, Putumayo, Caquetá, Meta y Valle.

- La forma principal de organización social es el cabildo, como entidad encargada de ejecutar la voluntad de Asamblea que es la máxima instancia de toma de decisiones.

\section{Formas de producción}

- Modelos de producción de las etnias caucanas:

- Producción agroecológica

- Autonomía alimentaria

- Sistemas de financiamiento alternativos

- Formas de comercialización, locales y externas

- Formación de personal propio que dinamice procesos productivos

- Investigación local, organización administrativa, gestión y planeación productiva, bajo un concepto de participación, gobernabilidad local, sostenibilidad ambiental y equidad de género

- Criterios que rigen el modelo de economía propia:

- Producción agroecológica

- Control territorial

- Construcción de capital social y humano

- Capital institucional

- Gobernabilidad

- Competitividad

- Sostenibilidad

\section{CADENAS PRODUCTIVAS}

En el contexto indígena podríamos identificar que la cadena productiva es un conjunto de actividades estrechamente interrelacionadas y verticalmente asociadas por su vinculación a un mismo producto que, a través de la integración de los productores y actores que intervienen en los procesos de producción, investigación, transferencia de tecnología, procesamiento, comercialización y financiación, buscan planear y organizar actividades económicas cuya finalidad es el desarrollo endógeno y la participación justa en los mercados donde colocan sus productos.

- Producción en zona indígena Páez:

- Encadenamientos productivos: seda, chontaduro, guadua, panela-miel, totumo, artesanías

- Regionalización de las actividades productivas dinámicas

- Tendencia al asociativismo 
- Limitaciones para el desarrollo de procesos productivos en minorías étnicas:

- Carencia de elementos para el trabajo, espacios funcionales, instalaciones físicas inadecuadas y desconocimiento de técnicas para el manejo y administración de la información y la documentación.

\section{Agrocadena de café en zona de Tierradentro:}

- Procesos de capacitación

- Fortalecimiento organizativo

- Inversión productiva

- Planeación/gestión

- Producción y comercialización.

\section{Variables encontradas}

- Cultura

- Organización social

- Relaciones económicas y de producción

- Manejo e interacción con el ambiente

- Sistemas de financiamiento.

\section{CONCLUSIONES}

Las minorías étnicas tienen manifestaciones culturales variadas, organización social y política, relaciones económicas y de producción, y manejo e interacción con el ambiente, con diversidad de formas de organización social basadas en relaciones de parentesco y comunitarias con multiplicidad de estructuras que determinan condiciones específicas como el tipo de alianzas, la residencia, la descendencia y la filiación; variadas formas de gobierno con autoridades tradicionales de carácter ancestral y otras adecuadas a los procesos de interacción con la sociedad nacional: formas de producción y de comercialización con mano de obra familiar y comunitaria, predominantemente destinadas a la autosubsistencia o al intercambio en pequeña escala con manejos, generalmente, equilibrados en cuanto al uso y apropiación de recursos naturales.

En Colombia existen más de 84 etnias indígenas distintas, organizadas de acuerdo a unas leyes internas diferentes a las nacionales, regidas por unas formas de gobierno y autoridad también diferentes, y con un control territorial más o menos amplio si se considera que poseen cerca de 27 millones de hectáreas de tierra equivalentes a una cuarta parte del país. Igualmente en algunas regiones del país son mayoría demográfica, caso de Caldono y Silvia en el Cauca, y sus territorios tienen una importancia estratégica para el devenir de Colombia, puesto que, entre otras cosas, corresponden a ecosistemas muy valiosos y a fronteras internacionales. 
Las actividades productivas que han adquirido especial dinamismo en los últimos años, unas surgidas de emprendimientos individuales y otras de emprendimientos colectivos, son entre otros: seda, chontaduro, guadua, panela-miel, totumo, artesanías. Otros frentes dinámicos: turismo, cafés especiales, frutales, apicultura, plantas medicinales y aromáticas, quinua y amaranto, proyectos productivos del programa Tierradentro, confecciones, metalmecánica, maderas, fique, leche, cueros, alimentos y orfebrería.

Se reconoce en los espacios ocupados por las minorías étnicas, una serie de limitaciones para el desarrollo normal de las tareas inherentes a los diversos procesos productivos. La carencia de elementos para el trabajo, de espacios funcionales, las instalaciones físicas inadecuadas y el desconocimiento de técnicas para el manejo y administración de la información y la documentación. Por tanto, la problemática se puede visualizar como deficiencia económica-productiva, técnicoadministrativa, y político-organizativa.

Los modelos de producción de las etnias caucanas incluyen la producción agroecológica, bajo el concepto de participación, gobernabilidad local, sostenibilidad ambiental y equidad de género y generacional, con cadenas productivas, autonomía alimentaria, sistemas de financiamiento alternativos, formas de comercialización locales y externas, formación de personal propio que dinamice procesos productivos, investigación local, organización administrativa y, gestión y planeación productiva.

El modelo de economía propia se sustenta en el beneficio comunitario y no en el carácter de acumulación en pocas manos, por tanto la redistribución es el principio fundamental de esta economía indígena. El modelo de economía propia en regiones como Tierradentro, en el departamento del Cauca, está basado en un conjunto de prácticas culturales y sociales enmarcadas en la agricultura orgánica y cuenta con potencialidades y oportunidades relacionadas con la visión de justicia social, dentro del ámbito económico, el alto grado organizativo, el sentido de unidad y la capacidad para llegar al consenso.

Hay productos que por su dinámica económica en la región y en el país generan, mediante sistemas de mejoramiento productivo, volúmenes representativos de productos como el café y el fique en la etnia Páez, plantas aromáticas y condimentarias en la etnia Totoroe, carne de trucha en los Yanaconas, todos estos del sector indígena, y, caña panelera, frutales y cacao en la población negra, ejemplos de dinámicas económicas que se ajustan a la visión productiva actual de estos pueblos.

En el contexto indígena podríamos identificar que la cadena productiva es un conjunto de actividades estrechamente interrelacionadas y verticalmente asociadas por su vinculación a un mismo producto, que a través de la integración de los productores y actores que intervienen en los procesos de producción, investigación, transferencia de tecnología, procesamiento, comercialización y financiación, buscan planear y organizar actividades económicas cuya finalidad es el desarrollo endógeno y la participación justa en los mercados, satisfacer al consumidor propio y a mercados justos, principalmente, de países de la Unión Europea donde colocan sus productos. 


\section{REFERENCIAS BIBLIOGRÁFICAS}

ASOCIACIÓN DE CABILDOS JUAN TAMA. Pensamiento ancestral, por la construcción del tejido social y el fortalecimiento de las relaciones interculturales. Programa Tierradentro. 2004.

BERDEGUE, Julio y LARRAÍN, Bárbara. Cómo trabajan los campesinos. Cuadernillo de Información Agraria nro. 18. Temuco (Chile): Grupo de Investigaciones Agrarias. Universidad de Temuco. 1987.

CENSO de los resguardos años 1999-2000 y DNP.

CONSTITUCIÓN POLÍTICA. Artículos 7 y 8, ratifican mediante la ley 21 de 1991, el Convenio 169 de la OIT sobre pueblos indígenas y tribales en países independientes.

CONVENIO CRC-CRIC. Plan Ambiental Indígena. 2002.

CORPORACIÓN AUTÓNOMA REGIONAL DEL CAUCA(CRC). Plan de Acción Trianual. 2004-2007.

CORPORACIÓN AUTÓNOMA REGIONAL DEL CAUCA. Plan de Gestión Ambiental regional del Cauca $2002-2012$.

CORTE CONSTITUCIONAL. Protección de los Raizales de San Andrés y Providencia.

DECRETO estatal 79 de 1828.

DOMÍNGUEZ, C. Construcción social del Espacio, en Historia Geografía y Cultura del Cauca. Territorios posibles. Tomo I.

FUNCOP. Elementos de Jurisdicción Especial indígena y prácticas comunitarias de justicia. Julio de 2001.

GAMBOA, J. C. et al. Los gitanos en Colombia. Límites y posibilidades de la invisibilidad como estrategia de resistencia étnica. En: Carlos Vladimir Zambrano, Etnopolíticas y racismo. conflictividad y desafios interculturales en América Latina. Bogotá (Colombia): Facultad de Derecho, Ciencias Políticas y Sociales. Universidad Nacional de Colombia. 2002.

ITURRALDE, D. La gestión de la multiculturalidad y la multietnicidad en América Latina. En: MARTÍNEZ COBO, J. Descripción de los pueblos indígenas. Relator Naciones Unidas.

LEY 89 de 1890, emanada del Estado. 
LEY 23 de 1991 que crea la conciliación en equidad, la jurisdicción especial indígena (artículo 246) y la creación de la jurisdicción de paz (artículo 247).

LEYES 60 de 1993, 152 de 1994, 388 de 1997, 115 de 1994, 397 y ley 100 de 1993.

MINISTERIO DEL INTERIOR Y DE JUSTICIA. Dirección de Etnias. Décimo y Onceavos Informes Combinados al Comité para la eliminación de todas las formas de discriminación racial. Bogotá, D. C., marzo de 2003.

PDHRE. Declaración de los derechos de las personas pertenecientes a minorías nacionales étnicas, religiosas y de idioma. Artículos 1 a 4.

PÉREZ, R. y ARMENDÁRIZ, L. La lumea de noi. Nuestra Gente. Memorias de los ludar de México. (2001, compiladores). México, D. F.: CONACULTA-FONCA-PACMYC.

PROGRAMA TIERRADENTRO. Economía Propia, Colección de sistematización. En: Revista 3 de 2004.

PROGRAMA TIERRADENTRO. Medio ambiente. En: Revista 4 de 2004.

PROGRAMA TIERRADENTRO. Rostros y voces del manejo Agroambiental. En: Tierradentro, Cartilla 1 de 2004.

PROGRAMA TIERRADENTRO PT-CW. Proyectando futuro desde el pasado y el presente de la comunidad de Tierradentro.

RESOLUCIÓN 15 de octubre de 1828, emanada del Estado.

ROJAS MARTÍNEZ, A. Si no fiera por los quince negros, Memoria colectiva de la Gente de Tierradentro. Popayán: Editorial Universidad del Cauca. Marzo de 2004.

YULE, M. Ponencia sobre Educación Ambiental en los Pueblos Indígenas. 1996.

\section{CIBERGRAFÍA}

$<$ www.dnp.gov.co $>$

$<$ www.nacionesunidas.org.co $>$

$<$ www.unesco.org/most.iturspan.html>

$<$ www.un.org/esa/socdev/pfii> 